\title{
mssaico
}

\section{A questão da autoria: o caso de Alexandre Dumas}

\section{Isabella Nogueira $^{1}$}

\section{The issue of}

authorship: the case of Alexandre Dumas 


\section{Resumo:}

A partir do caso de Alexandre Dumas pai e seus colaboradores vamos falar sobre a questão da autoria. A pergunta inicial é: quem é o autor? Segundo Foucault, no texto O que é um autor (1969), o importante é buscar a dimensão do texto além do próprio nome do autor. Porém, a dimensão individual deve criar um equilíbrio entre vida e obra. Portanto, queremos pensar o que esses escritos trazem para além do autor e o que este traz para esses escritos. A partir do caso Dumas, vamos questionar essa figura autor, fundamental nos estudos da História e da Literatura.

Palavras-chave: História e Literatura, Alexandre Dumas, Autor, Romantismo, Século XIX.

\section{Abstract:}

Through the case of Alexandre Dumas father and his collaborators we are going to talk about the question of authorship. The first question is: who is the author? According to Foucault, in his essay What is an author? (1969), the point is to search beyond the text besides the author's own name. However, the individual dimension must create a balance between the life and the work. Therefore, want to think what these writings bring beyond the author and what it brings back to these writings. From Duma's case, we are going to question this author's figure, central to the studies of History and Literature.

Keywords: History and Literature, Alexandre Dumas, Author, Romanticism, 19th century. 
Voilà, monsieur Dumas, ce qu'est devenue la littérature entre vos mains. Traite avec vous la question d'art serair perfaitemont inutile. Vous ne connaissez que deux choses, fabriquer et vendre; fabriquer beaucoup pour vendre davantage. (...) II faut pourtant établir une exception pour vous, monsieur Dumas: vous signez tout et ne soignez rien. Mais la question d'argent l'emporte à vos yeux sur une foule d'autres considérations. (...) C'est-à-dire, entendons -nous, de fabricants. Vous devinez bien que, pour M. Dumas, la collaboration represente le repôs, le far niente, le doux loisirs, le divan d'une maîtresse, la dètonation du champagne, les bels masques, les voyages en poste, le joies de Florence, les courses en Suisse, les biftecks d'ours et une foule de choses gracieuses, dont il n'aurait pas le bonheur de jouir si, par-ci, par-là, il ne confiait à d'autres la confection d'une chefd'oeuvre. Dieu s'est reposé le septime jour de la création. Par consequente, vite à la besogne, messieurs Anicet, Durieu, Brunswick, Cordelier-Delanoue, Goubaux et Beudine, Maquet, Dennery, tous les fidèles de mon atelier Théâtral!(...) Cette longue et pénible histoire de notre littérature moderne peut se résumer par um seul mot, l'ARGENT. (MIRECOURT, 1845, p.51) ${ }^{1}$

Cada vez que se quis atingir Alexandre Dumas, todos foram pelo mesmo caminho, a autoria. Questionava-se sua habilidade em escrever com tanta frequência, em tão pouco tempo, e seus privilégios com os editores, se estes estavam conscientes de suas atitudes. Diferente dos outros escritores românticos conhecidos, Dumas teve uma formação débil, fato que sempre marcou seu nome.

Em 1845, Eugène de Mirecourt (que se chamava Jean-Baptiste Jacquot), escritor contemporâneo de Alexandre Dumas que iniciou sua carreira em 1836 com a obra Sortir d'un réve (MORAND, 1855), escreveu um folheto em que fazia duras acusações a Alexandre Dumas, uma crítica a Dumas \& Cia, porém, não desejava nada mais do que trabalhar para personagens como o escritor de Os três mosqueteiros. Antes de escrever essa crítica, bem articulada em 81 páginas, Mirecourt já tinha se dirigido a Dumas propondo-lhe um enredo para um romance, ao que este recusou. Sentindo-se rechaçado, Mirecourt, dirigiu-se à Sociedade dos Homens de Letras para protestar contra o sistema literário, que não deixava aos demais autores espaço suficiente para ganhar a vida. Denunciava uma indústria dirigida

\footnotetext{
1 “Eis aí senhor Dumas, o que se tornou a literatura entre suas mãos. Tratar com o senhor sobre a questão da arte é perfeitamente inútil. Não conheceis senão duas coisas, fabricar e vender. Produzir muito para vender ainda mais. [...] Mas temos que estabelecer uma exceção para o senhor Dumas: assinais tudo e não cuidais de nada. O dinheiro é mais importante aos vossos olhos do que uma série de outras considerações. [...] Ou seja, entendamo-nos bem, os fabricantes. Você deve supor que, para Dumas, a colaboração representa o resto, o fazer nada, o doce prazer, o sofá de uma amante, o desarrolhar de um champanhe, as máscaras bonitas, a viagem publicada nos jornais, as alegrias de Florença, compras na Suíça, bifes de urso e uma série de coisas graciosas, de que ele não teria a felicidade de desfrutar se, um por um, ele não tivesse confiado aos outros a realização da obra prima. Deus descansou no sétimo dia da criação. Por conseguinte, passem rapidamente às obrigações, aos senhores Anicet, Durieu, Brunswick, Cordelier-Delanoue, Goubaux et Beudine, Maquet, Dennery, todos os fiéis do meu ateliê teatral. [...] Essa longa e dolorosa história da nossa literatura moderna pode ser resumida em uma palavra, DINHEIRO". (Tradução livre).
} 
por poucos, que guardavam para si todos os privilégios. Repelido mais uma vez, decide escrever uma carta a Émile de Girardin, diretor do jornal La Presse, pedindo-lhe que fechasse as portas para Dumas e toda sua fábrica, uma vez que tratava-se de um mercantilismo vergonhoso. Sua sugestão era que franqueasse espaço para jovens promissores, fazendo alusão a si mesmo, no entanto, Girardin respondeu-lhe que o público queria Dumas e que ele o manteria. Essa última resposta desencadeou em Mirecourt ódio suficiente para escrever sua crítica, que tornou-se bem articulada por ter tido a confidência de colaboradores insatisfeitos. Ela teria sido até válida se não fosse o fato de Mirecourt ter demonstrado sua má-fé insultando Dumas com palavras vulgares (MAUROIS, 1959, p.184). Começou falando de sua origem e elencou, de modo pejorativo, o quanto Dumas tinha de marquis e de nègre. O marquis que é de conhecimento de todos, diz ele, está longe da epiderme de Dumas, o qual desempenha seu papel de marquis em público e deixa o de nègre traí-lo na intimidade (MIRECOURT, 1845, p.17-18). Além disso, atacava a vida privada dele, zombando de Ida Ferrier, seu affair da época, e preocupou-se também em expor um cálculo matemático para demonstrar a impossibilidade de Dumas escrever tanto.

Vous avez publié TRENTE-SIX volumes dans le cours de l'année 1844, monsieur Dumas, et, pour l'année 1845, vous em annoncez le DOUBLE. Eh bien, nous allons fair ele simple calcul que voici: Le plus habile copiste, éscrivant douze heures par jour, obtient à peine 5,900 lettres à l'heure, ce qui lui donne, as journée finie, 46,800 lettres, ou 60 pages ordinaires de roman. Donc il pourra copier cinq volumes inoctavo par mois et soixante par an, mais à condition qu'il ne s'arrêtere pas une heurre et ne perdra pas une seconde. (MIRECOURT, 1845, p.48) ${ }^{2}$.

Todos sabiam e contribuíam para o crescente comércio literário denunciado por Mirecourt, porém, sua argumentação foi tão violenta que o efeito de denúncia desapareceu, dando espaço a um elenco de comentários concordantes a favor de Dumas. Esse também foi o caso de Balzac, que, não tendo um ótimo relacionamento com Dumas, poderia ter-se entusiasmado com o julgamento. Contudo, vemos em suas palavras não uma total reprovação à denúncia e sim à forma como ela foi articulada. Ele escreveu: "Deram-me o panfleto Dumas \& Cia. É ignobilmente estúpido, mas é tristemente verdade. E como, na França, acredita-se mais facilmente numa calúnia espirituosa que na verdade estupidamente articulada, isto pouco mal causará a Dumas." Não foi só aos leitores e colegas de Dumas que essa crítica causou repugnância, mas também aos tribunais. Mirecourt foi condenado a quinze dias de prisão e a publicação da sentença nos jornais fez com que ele ficasse desacreditado no meio literário por um tempo. Para piorar sua situação, em 1857, um certo Rochefort, sob o título de Eugène de Mirecourt \& Cia, por um associado, afirma que o autor também se utilizava de colaboradores, sendo ele próprio um deles, e ironicamente

\footnotetext{
2 "O senhor publicou TRINTA E SEIS volumes durante o ano de 1844, Senhor Dumas, e para o ano 1845 anuncia o DOBRO. Bem, vamos fazer um simples cálculo: o mais hábil copista, escrevendo doze horas por dia, mal escreve 5900 letras por hora, dando ao final do dia 46800 letras ou 60 páginas de um romance comum. Portanto, ele vai copiar cinco volumes in-octavo [formato de uma folha de impressão dobrada em oito partes] por mês e sessenta por ano, desde que ele não pare por uma hora e não perca um segundo.". \{Tradução livre\}
} 
argumenta que pagava pior que Dumas, mas essa é outra história. Para confundir mais as ideias de Mirecourt, Auguste Maquet partiu em defesa de Dumas (MAUROIS, 1959).

Auguste Maquet, em 4 de março de 1845, escrevera uma carta a Dumas dizendo-lhe que dispensava a inserção de seu próprio nome nos escritos que fizeram juntos:

\begin{abstract}
Declaro renunciar, a partir desta data, a todos os direitos de propriedade e de reimpressão sobre as obras seguintes, que juntos escrevemos, a saber: 0 Cavaleiro de Harmental; Silvanira; Os Três Mosqueteiros; Vinte Anos Depois; O Conde de Monte Cristo; A Guerra das Mulheres; A Rainha Margot; O Cavaleiro de Maison-Rouge, considerando-me definitivamente e devidamente indenizado por $\mathrm{ti}$, de acordo com o que verbalmente convencionamos. Guarda essa carta, caro amigo, para mostra-la aos herdeiros ariscos e dizer-Ihe claramente que, enquanto vivi, sentia-me muito feliz e muito honrado de ser colaborador e amigo do mais brilhante dos romancistas franceses. Que ele faça como eu. (D'ALMÈrAS apud MAUROIS, 1959, p.184).
\end{abstract}

Mais tarde, quando a carta tornou-se pública, durante a briga de Maquet e Dumas na justiça, pois aquele pedia uma soma exorbitante por direitos autorais, o primeiro afirmou ter sido a carta arrancada dele a contragosto. Contudo, suas alegações não foram completamente aceitas: a Justiça determinou o pagamento de royalties suplementares, mas negou-Ihe a assinatura de coautoria (DUMAS,2012).

Anos antes, Dumas tivera problemas parecidos também com o escrito A Torre de Nesle, peça que foi publicada em 29 de maio de 1832. "Dès 1831, Frédéric Gaillardet avait revendiqué davant les tribunaux - qui lui donnèrent saticsfacion - la propriété de la Tour de Nesle que Dumas s'etait contenté de retoucher et de signer" (D'ALMĖRAS,1929, p. 46) ${ }^{3}$. Há indícios de que dessa vez Dumas não estava interessado na autoria, apenas tinha pedido que ganhasse seu dinheiro em proporção à fama da peça, quem quis colocar seu nome foi Harel, que considerava que o nome Dumas poderia trazer mais pessoas e consequentemente mais dinheiro, por causa de seu sucesso com Henrique III e sua corte. Contudo, Dumas, mais tarde, quando tudo já tinha passado e os pequenos jornais não colocavam mais em dúvida a autoria, acabou apropriando-se da obra, e em suas memórias, apenas comenta o sucesso que teve. Porém, na época, ainda no início da carreira de Dumas, esse ocorrido tivera uma desagradável repercussão. Agravando esse episódio, mais tarde, no Journal des Débats, Granier de Cassagnac acusou Dumas de ter imitado Schiller, Goethe e Racine e de ter buscado inspiração para sua peça Cristina, no quinto ato de Hernani, da peça de Victor Hugo, Maria Tudor. Dumas escreveu uma carta a Hugo, dizendo-Ihe que foi este último quem pediu para que Cassagnac escrevesse esse artigo, e acusou-o de conhecer bem aquele texto. Hugo não defendeu-se, mas Cassagnac o fez novamente, em novo artigo (MAUROIS, 1959, p. 132138). Além disso, em 1843, Louise Loménie e Sainte-Beuve denunciaram a literatura

\footnotetext{
3 “Em 1831, Frédéric Gaillardet reivindicou junto aos tribunais - que acataram seu pedido - a propriedade de $A$ Tour de Nesle, que Dumas tinha se contentado em editar e assinar." (Tradução livre).
} 
industrial, sem deixar de lado o nome Dumas. Loménie escreveu:

Atingido por esse deplorável contágio de industrialismo, praga da época, o Sr. Dumas, podemos e devemos dizê-lo, parece devotado de corpo e alma ao culto do bezerro de ouro.(...) É fisicamente impossível que o Sr. Dumas escreva ou dite tudo o que surge - por ele assinado. (LOMÉNIE apud MAUROIS, 1959, p. 184).

Mirecourt também equivocou-se ao dizer que apenas Dumas utilizava-se de colaboradores, pois muitas vezes os escritores compartilhavam entre si os mesmos, como foi o caso de Félicien Mallefille de Dumas com George Sand ou Paul Meurice e Auguste Vacquerie com Victor Hugo ou Balzac, que teve vários enredos para suas obras dados ou sugeridos - como é o exemplo de Beatrix -, por George Sand (MAUROIS, 1959, p. 186). Dumas não falará disso em suas memórias, porém, alega em sua defesa: "Meu maior desejo é ilimitado; minha aspiração primeira é sempre pelo impossível. Como faço para realizá-lo? Trabalhando como ninguém trabalha, cortando da vida todas as suas pequenezas, roubando ao sono" (MAUROIS, 1959, p. 182).

E o que Dumas pensava sobre isso? Por mais que ele não tenha dado muita importância às acusações, sempre mostrou importar-se com os títulos e as definições atribuídas não só à sua pessoa, mas principalmente ao Dumas hommes de lettres. Aquele desejo de ser conhecido, reconhecido e exaltado o fez buscar, em 1840/1841, a Academia Francesa para a ela ser eleito. Dumas ficou bastante agitado para conseguir esse intento e isso fez com que outros o criticassem, como, por exemplo, Jules Janin ou Sainte-Beuve, que nunca negaram as habilidades do autor, mas não o consideravam um Victor Hugo. Este último foi eleito em 1841 pela Academia, deixando Dumas desapontado, afinal, ele não se via diferente de Hugo. Não queria apenas ser famoso, era necessário ser reconhecido ao mesmo patamar, ou acima, de seu amigo/inimigo Hugo. Havia, por parte do literato, uma admiração banhada a competição por esse último. Dumas esforçou-se e esperneou, mas nunca conseguiu obter o respeito que Hugo obtivera em vida.

"A eleição de Victor Hugo permitia a toda geração romântica alimentar esperanças" e Dumas também as alimentou enquanto questionava a demora de sua eleição. O próprio Hugo pensava que "[a]s Academias, como todo o resto, pertencerão à nova geração. Enquanto ela espera eu serei a brecha viva por onde hoje penetram essas ideias e por onde esses homens entrarão amanhã". Eram esses homens "Vigny, Dumas, Balzac e mesmo seu inimigo Sainte-Beuve, pois tinha uma grandeza de alma". Ao contrário dos demais, Dumas só estava preocupado consigo próprio (MAUROIS, 1959, p. 159). Assim, desde 1839 ele reclamava a François Buloz, diretor da Revue des Deux Mondes, revista na qual publicava suas impressões de viagem, sobre essa demora: "Fala, pois, de mim, na revista, para a Academia e pergunte a si mesmo como é que não estou entre os seus membros quando já Ancelot se candidata". Em 15 de janeiro 1841, volta a escrever: "Fala um pouco de mim nas suas crônicas para a Academia. Não faço parte dela mas quero que estranhem esse fato" (MAUROIS,1959). Não contente o bastante, após a eleição de Hugo, Dumas entra em contato 
com Nodier para alertá-lo da incoerência da Academia e para pedir-lhe um auxílio:

Julgas que neste momento eu teria possibilidade de entrar para a Academia? Hugo entrou. Se todos os seus amigos fôssem mais ou menos meus amigos também... Se notares que a coisa ganha alguma consistência, sobe a Tribuna da Academia e dize em meu nome, a teus veneráveis confrades, que eu gostaria de figurar entre eles... Enfim, dize a meu respeito tudo o de bom que pensas e mesmo aquilo que não pensas. (MAUROIS, 1959, p.160).

$\mathrm{Na}$ verdade, nunca conseguiu entrar para a Academia, nem mesmo Balzac, seu segundo maior rival, mas os interesses eram diferentes, como também as atitudes. Contudo, havia aqueles que defendiam Dumas, como é o caso do Visconde de Launay, pseudônimo de Delphine de Girardin escritora e esposa de Émile de Girardin diretor do jornal La Presse:

É, pois, inconveniente ser famoso? - perguntava encolerizada Delphine de Girardin. - Por que os talentos famosos tem tanta dificuldade para entrar? É pois um crime ter direitos? ... Balzac e Alexandre Dumas escrevem de quinze a dezoito volumes por ano e isto é imperdoável. "Mas os romances deles são excelentes. - Não é desculpa. São muito numerosos. Mas têm um êxito louco! - Um defeito a mais: eles que escrevam apenas um, bem pequenino, medíocre, que ninguém leia. Então, veremos". Uma bagagem muito grande é um empecilho. Na Academia o lema é o mesmo do jardim das Tuileries: não se deixa entrar os que levam embrulhos muito grandes... (MAUROIS, 1959, p.160)

Na verdade, a Academia Francesa assustou-se com o "escândalo", Dumas, era conhecida sua vida agitada e extrema e ele vivia no limite em todos os aspectos, principalmente aqueles das relações pessoais e econômicas, pois gastava mais do que ganhava, e não ganhava pouco. Os indivíduos pertencentes aos órgãos oficiais consideravamno agradável, mas não sério o suficiente para ter o prestígio de representar a Academia. Esse acontecimento foi, de certo modo, uma derrota para Dumas, que, em 1860, já se sentia distante do meio literário francês e, principalmente, daqueles ilustres escritores. No entanto, nunca deixou de lutar pelo prestígio que considerava merecer (MAUROIS, 1959, p.160).

Não foi só Mirecourt, Leménie ou Sainte-Beuve que tiveram essa dúvida quanto à autoria, ela nos veio também quando colocamos como objetivo estudar a circulação da obra Mémoires de Garibaldi (1860). Nesse sentido, acabamos por fazer uma "revisão do papel do indivíduo (iluminado - senhor de si) como autor dos discursos". Entra em questão, então, a preocupação com a subjetividade que se estende do autor ao personagem. (CAVALHEIROS, 2008, p. 69).

Garibaldi escreve e Dumas comenta e publica: essa declaração, escrita na capa do livro, parece querer tirar qualquer dúvida quando ao processo de composição da obra. 
Contudo, uma análise mais atenta mostrará que a relação entre os dois e os escritos é um pouco mais complexa. Há todo um cenário que favoreceu o andamento da publicação do livro, a começar pelo fato de que Garibaldi entregava, sempre que podia, seu manuscrito para ser publicado por alguém. Não parece ser uma atitude diferente daquela dos colaboradores de Dumas. Poderíamos até escrever que Garibaldi foi um deles, uma vez que isso teria possibilitado, à época, que Dumas escrevesse e publicasse muito sobre a Itália.

No meio a esse emaranhado de acusas e defesa, a pergunta que fica é: quem é o autor? Mesmo que agora queiramos definir que é Dumas, resta ainda a pergunta quem é o autor/Dumas? E a elas se adicionam outras: importa quem é o autor? $\mathrm{O}$ autor morreu? $\mathrm{E}$, por fim, "o que é um autor?".

Diríamos, inicialmente, que o autor é uma figura "exterior e anterior ao texto", pelo menos em aparência, visto que essa escrita é dominada, inicialmente, por duas regras que abarcam dois grandes temas, a saber: o tema da morte e o tema da expressão. O primeiro conferiria imortalidade ao autor ou adiaria a morte, enquanto o segundo articula-se entre dois extremos que vão do texto diz tudo ao leitor diz tudo. Sem embargo, esta seria uma argumentação mínima para o tema (CAVALHEIROS, 2008, p.70). Contudo, antes de começarmos esta discussão, é importante dizer que não foi sempre na história que se teve uma preocupação constante com o autor, essa começou a surgir a partir do momento em que se principiou a pensar os privilégios do indivíduo e a sua contenção.

No período de Dumas até mesmo a nomenclatura modificava-se constantemente, por conta das novas discussões. Geralmente os homens de letras eram designados como génie ou poète, o primeiro "dando ênfase ao caráter sagrado da prática", o segundo, "partindo da poesia como fonte primordial de inspiração". Victor Hugo era frequentemente denominado pelos dois nomes. Balzac, contudo, não referia-se a esses dois termos a não ser de forma irônica, como, por exemplo, para definir alguma personagem vaidosa; prefere a palavra historien e às vezes emprega a palavra auteur quando quer falar da comercialização de seus livros e não do processo criativo. De forma geral eram designados hommes de lettres, mas, em 1839, o termo utilizado era gens de lettres, que, se antes expressava uma bajulação, logo em seguida passou a ser usado de "modo ridicularizante" (MENDES, 2008, p.03).

Se até meados do século XIII não existia a preocupação em definir a figura do autor, a partir do século XIX isso se torna uma preocupação constante, mesmo que não seja comparável com a que temos nos dias de hoje. Da Antiguidade até a Idade Média, não havia preocupação com quem escrevia a obra ou mesmo com quem a publicaria, existia uma livre circulação de histórias que estavam à disposição dos processos de criação dos contadores. Eles podiam acrescentar, modificar ou melhorar de acordo com que achavam necessário. 0 próprio anonimato dava uma ideia de autenticidade da obra, a forte circulação, nesse caso apropriação do texto, dava sua antiguidade e por isso sua autenticidade; interessavam as verdades necessárias no texto para serem aplicadas a compreensão e explicação antes do imortal e depois do cotidiano. 
A partir da Idade Média, essa figura sofre modificações. Era necessário saber quem era o autor, estabelecer sua identidade, para poder monitorar os escritos heréticos e assim punir a transgressão. Livros eram queimados e as pessoas podiam até ser condenadas à morte como forma de demonstração, para os demais, da impossibilidade de se voltar contra as autoridades, ou seja, o poder religioso e político, principalmente o primeiro. Mas ainda não existia à época o reconhecimento do direito autoral. (CHARTIER, 2012, p. 49) Há então a Renascença que por uma série de motivos políticos, econômicos e culturais se verifica uma exaltação do indivíduo, que na arte significa rever o papel do autor.

Quando falamos em reconhecimento autoral, que para Foucault está ligado a sustentação e construção da função autor, encontramos duas hipóteses em contraste. Para Foucault ocorreu quando começou-se a definir a propriedade burguesa: "quando se instaurou um regime de propriedade para os textos, quando se editam regras estritas sobre os direitos do autor, sobre as relações autor-editores, sobre as direitos da reprodução etc. Ou seja, no fim do século XVIII e no início do século XIX" (FOUCAULT, 2006, p. 275) que a transgressão que pertencia ao ato de escrever passou a ser um imperativo próprio da literatura. Chartier concorda com Foucault quando diz que o reconhecimento autoral está ligado à construção da função autor, contudo, pontua que a propriedade literária "é no interior da defesa do direito do livreiro editor, e não do autor, que ela se precisa" (CHARTIER, 2012, p. 42). No entanto, esta emergência em definir propriedade não é "a expressão possível de um novo direito burguês, mas um engajamento a serviço da perpetuação de um velho sistema de privilégios" (CHARTIER, 2012, p. 46). Não é a mesma ideia de propriedade que hoje consideramos, que podemos aplicar para a época, até porque durante esse período, a Alta Idade Média, exceto livros das autoridades religiosas, jurídicas ou antigas era de costume escrever livros em conjunto, com vários autores, os conhecidos zibaldone. Outro caso é o exemplo do teatro no qual, o autor era aquele que comprava, organizava e preparava o espetáculo, e não o escritor da peça.

Quando chegamos ao século XIX, a discussão sobre autor ou propriedade autoral não é novidade, porém, um novo sistema de relações econômicas, políticas e culturais está se instaurando e como tudo que faz parte da vida a questão autoral entra em uma nova discussão. Há um florescimento do indivíduo, para Gay (1999), quase uma neurose com o "eu", há uma consciência da ação do homem sobre as coisas, uma nova consciência sobre o tempo e a natureza.

O romantismo associado a esse período não foi só uma revolução literária, e sim uma revolução geral dos valores. Bénichou (2013) fala-nos de um poder espiritual novo, no qual ocorre uma consagração do escritor que se propôs a pensar o mundo com outros olhos e a rever a narrativa sobre ele. Um espírito romântico que perpetuava todos os campos da vida, tanto econômico e político quanto cultural.

Pour le romantisme, le Poète, chercheur, interprète et guide, est au centre du monde de l'esprit, dont le prête ne détient plus qu'une des versions possible. Telle est la nouveauté qui fait du romantisme le signe d'um 
bouleversement profond.(...) Finalement chaque parti a fait comprendre à l'autre ce que ses vues avaient d'insuffisant, et une sorte d'unité romantique est née, qui a consacré la ruine de l'ancien ordre spiritual et inaugure le nouveau. (BÉNICHOU, 2013, p. 276) ${ }^{4}$

Durante essa nova consagração do escritor, exposta por Bénichou, ocorreu um novo olhar para o escritor, no entanto, esse novo olhar não estava só ligado à questão individual da figura e sim à nova estilística que estava surgindo: o discurso romântico. Este influenciou essa nova ordem do que hoje chamamos de Literatura.

A função autor, pensada por Foucault, caracteriza a circulação e o funcionamento dos discursos nas diferentes sociedades. A marca do autor não é nada mais do que a singularidade da sua ausência, contudo, não há uma morte do autor, já que este preserva sua existência em duas noções: aquela da obra e a da escrita. Na primeira não é possível apagar a figura do autor e deter-se na obra, já que a questão da individualidade é tão complexa quando aquela da obra; na segunda, trata-se do "empirismo do autor, tanto pela necessidade do comentário, quanto pela necessidade de interpretação, respectivamente denominadas, por Foucault, de modalidade crítica e modalidade religiosa" (CAVALHEIROS, 2008, p. 70). Assim, estudar a função autor nos levaria a não só pensar na discursividade apresentada, mas também em sua materialidade, que se dá, por exemplo, pelo estudo de sua produção e de seu cenário, os quais caracterizam o processo que constrói a figura que chamamos autor. Desse modo, ao lado da discursividade, Chartier considera que é de fundamental importância que pensemos na materialidade do discurso, ou seja, no livro. Esses pontos são indissociáveis, bem como a tensão que existe entre "escritor e indivíduo" ou "autor como ficção e o sujeito como ego" (CHARTIER, 2012, p. 63).

Se Foucault estava mais interessando em pensar a questão autor no emaranhado das relações de poder, Barthes (2012), com seu texto A morte do autor, estava preocupado em discorrer sobre a dificuldade de precisar de quem é a voz. Neste sentido ele nos diz que não é o autor quem fala, mas a linguagem, ou seja, o sujeito nunca escreve nada que já não foi dito, a linguagem já está dada e por isso não há uma antecedência entre o escritor e o texto que é eternamente escrito "aqui e agora". (BARTHES, 2012, p. 61) Nesse sentindo o escritor que é sucessor ao autor - "fora ou anterior à linguagem, porque o autor é entendido como sujeito social e historicamente construídos, isto é, um produto do ato de escrever", o qual faz o autor e não o contrário - no ato de escrever anula toda a voz, que é neutra, faz fugir o sujeito fazendo com que se perca toda a identidade, tanto aquela do escritor como aquela da escrita. Diminuindo a instância da autoria encontramos assim o aumento do poder do leitor.

\footnotetext{
4 “Para o romantismo, o Poeta, pesquisador, intérprete e guia, está no centro do mundo espiritual, do qual o padre não detém mais que uma das versões possíveis. Essa é a novidade que faz do romantismo o sinal de uma perturbação profunda. [...] Finalmente cada partido [contrarrevolucionário e o liberal] deixou claro para o outro o que seus pontos de vista tinham de insuficiente, e uma espécie de unidade romântica nasceu, que consagrou a ruína da velha ordem espiritual e inaugurou uma nova." \{Tradução livre\}
} 
Assim se desvenda o ser total da escritura: um texto é feito de escrituras múltiplas, oriundas de várias culturas e que entram umas com as outras em diálogo, em paródia, em contestação; mas há um lugar onde essa multiplicidade se reúne, e esse lugar não é o autor, como se disse até o presente, é o leitor: o leitor é o espaço mesmo onde se inscrevem, sem que nenhuma se perca, todas as citações de que é feita uma escritura; a unidade do texto não está em sua origem, mas no seu destino, mas esse destino já não pode ser pessoal: o leitor é um homem sem história, sem biografia, sem psicologia; ele é apenas esse alguém que mantém reunidos em um mesmo campo todos os traços de que é constituído o escrito. (BARTHES, 2012, p. 64).

A escrita, que é executada pelo escritor, mas organizada anteriormente pelo autor, considerando que a linguagem é anterior a este, segundo Barthes, é responsável, este último, pela mistura de escritas, "fazendo uma bricolagem de textos diferentes". Conforme esclarece Joachin Azevedo Neto, "Essa constatação, para Barthes, evidencia a inexistência de nexos entre escrita e vida. O escritor não escreve a partir de suas impressões e sentimentos, mas de imitação de signos já emitidos." (NETO, 2014, p. 155)

Concorda-se com Barthes quanto à ideia de bricolagem de textos diferentes, por exemplo, quando consideramos os escritos de Dumas. Várias vezes ele utilizava-se de textos existentes, muitas vezes reutilizando a sua própria escrita em vários outros livros. Quando vai escrever sobre Garibaldi essa é uma atitude constante; por exemplo, várias partes do livro Montevideo ou une Nouvelle Troie (1850) podem ser encontradas em seu jornal Le Mois (1848-1850) ou mesmo nas Mémoires de Garibaldi (1860). Entretanto, não consideramos que a partir dessa ideia evidenciamos uma inexistência de nexo entre vida e escrita. Mesmo que seja por imitação há eventuais características do escritor que se perpetuam em seus vários livros.

Bakhtin adverte que é assídua a confusão entre autor-pessoa e autor-criador, o primeiro, componente da vida, e o segundo, elemento da obra. O autor-criador é constituinte do objeto estético, é aquele que dá forma. Nessa ação, esse autor já se torna "o outro", é a consciência que abrange a consciência e o mundo da personagem e fornece um acabamento à imagem externa. Esse processo se dá pelo que Bakhtin chamou de excedente de visão estética do autor-criador. (CAVALHEIROS, 2008, p. 72)

Esse excedente da minha visão, do meu conhecimento, da minha posse excedente sempre presente em face de qualquer outro indivíduo - é condicionado pela singularidade e pela insubstitutibilidade do meu lugar no mundo: porque nesse momento e nesse lugar, em que sou o único a estar situado em dado conjunto de circunstâncias, todos os outros estão fora de mim. (BAKHTIN, 2011, p. 21)

A distância concreta de mim (autor) e de todos os outros indivíduos junto ao excedente de visão do autor, condicionada por mim e pela relação com cada um deles 
(indivíduos) são superados pelo conhecimento, que "constrói um universo único e de significado geral", totalmente independente "daquela posição única e concreta ocupada por esse ou aquele indivíduo". Não existe, para o autor, uma "relação absolutamente irreversível", um "eu e todos os outros". Há uma relação relativa e reversível para o conhecimento entre o "eu e o outro", "uma vez que o sujeito do conhecimento como tal não ocupa um lugar concreto determinado na existência" (BAKHTIN, 2011, p. 22).

O excedente não só torna o autor-criador "o outro" em relação ao personagem, mas também em relação ao autor-pessoa. Foucault dizia que textos do mesmo autor podem conter vários "eus", várias posições-sujeito, o que significa a pluralidade do indivíduo e a sua falta de singularidade, além das posições dos "eus" na apropriação do discurso.

No entanto, para Bakhtin, só é possível ter um acabamento quando o autor-criador regressa a si mesmo. $O$ excedente de visão humana é assim direcionado por uma diretriz axiológica.

Ao começar a escrever o texto Les Garibaldiens (1861), Dumas expõe, por meio de uma diretriz axiológica, mesmo que possa ser de forma inconsciente, o motivo de seu interesse pelo personagem Garibaldi. Isso ocorre porque as lutas pela unificação da Itália fazem com que reviva as injustiças que o pai sofreu naquelas terras, em mãos dos Bourbon, durante as campanhas napoleônicas. Caso ninguém até aquele momento tivesse dado o justo reconhecimento a esse homem, para Dumas ele era um herói e o faria apoiando e lutando, nem que fosse pela caneta, a causa republicana a que o pai tinha tanto apreço.

O autor-criador torna-se uma posição axiológica recortada pelo autor-pessoa, que, por sua vez, forma uma voz criadora. Nesse sentido, encontramos uma voz criadora que direciona para um equilíbrio, o autor-pessoa, o autor-criador e a multiplicidade de discursos do indivíduo na sociedade de que faz parte. Transporta assim, para o texto, a linguagem do dia-a-dia, da época, de um grupo social, de um gênero, de uma tendência, etc. Forma e conteúdo estão unidos no discurso, entendido como fenômeno social. (BAKHTIN , 1988, p. 82)

Essa articulação pode ser encontrada, por excelência, no discurso romântico que, diferentemente dos demais estilos, se caracteriza por ser um fenômeno plurilinguístico e heterogêneo, que repousa em planos linguísticos distintos, os quais estão submetidos a leis estilísticas diferentes das anteriores, ancoradas na poiêsis de Aristóteles (BAKHTIN, 1988, p. 72).

O romance é apresentado como o gênero em que se orquestra esteticamente uma diversidade social de linguagens. $O$ discurso do sujeito falante no romance, resultante de um conjunto múltiplo e heterogêneo de vozes ou línguas sociais, é representado artisticamente pelo próprio discurso do autor-pessoa - aquele que tem a fala refratada. É ele quem direciona todas as vozes alheias e entrega a construção do todo artístico a uma voz criativa. Essa voz, também refratada porque é uma voz segunda, do autor-criador, é uma voz social que ordena o todo estético. (CAVALHEIROS, 2008, p. 76).

$\mathrm{O}$ ato de composição do discurso romântico estaria ordenado pelo discurso do próprio autor, os discursos dos narradores, os gêneros intercalados, os discursos das 
personagens, em resumo, um romance seria composto por um plurilinguismo. $O$ autorpessoa libera-se de sua própria linguagem deslocando-se para o outro e, consequentemente, para outra linguagem. Sendo assim, o autor reconhece sua própria linguagem com o outro, e, portanto, sua própria visão na visão de mundo do outro. Há, assim, no romance, línguas sociais intercaladas entre as línguas do indivíduo e aquelas do social. A obra Mémoires de Garibaldi torna-se um romance a partir desse plurilinguismo, identificamos em seu corpo o ato de composição que agora a pouco falamos.

É ancorada a esse plurilinguismo do texto que ocorre a defesa da instância verdade do escrito. A importância dada ao autor durante o século XIX, bem como a sua consagração, se dava pelo nível de verdade que ele representava.

Em seu livro La Lecture et la vie: les usages do romanau temps de Balzac, Judith Lyon-Caen apresenta-nos o caso de Balzac e Sue, em que a adesão dos leitores ao projeto realista dos romances pode ser compreendida de duas formas: primeiro, tentavam estender, corrigir e influenciar o romance, processo feito muitas vezes por meios epistolares; segundo, utilizavam o esquema romântico para descrever o real, apropriando-se de palavras e situações expostas em um romance para seu próprio mundo e, logo, "tratam a ficção como um instrumento pertinente de desvelamento da realidade social"(CAEN-LYON, 2006). O autor, por sua vez, se apropriava de histórias sociais as quais ele dava um toque de estilo social e pessoal. Era importante para o autor, como também para o escritor, a proliferação de "eus" ao mesmo tempo em que se queria definir o próprio "eu". O colaborador, nesse sentido, ajudava não só materialmente o autor, mas também lhe possibilitava recorrer a mais visões possíveis, aplicáveis à composição da obra no social.

Desse modo, não podemos, como nos explica Dosse, separar o estudo do indivíduo do seu pensar, ou seja, da sua produção literária. Deve-se considerar cada escrito do autor mesmo que isso não signifique definir um todo por meio deles, pois nem mesmo pela própria biografia é possível fazer isso. É necessário que se estabeleça um equilíbro. “O existir e o pensar devem ser retomados juntos em seus respectivos recortes, numa abordagem que não dependa nem do internalismo nem do externalismo, mas enfatize, a fim de funcionar como ponte entre esses dois polos, aquilo que os psicanalistas chamam de atenção flutuante ao sujeito biográfico" (DOSSE, 2009, p. 369).

Torna-se inevitável, ao estudarmos obras do século XIX, a relação dos autores com o mundo que os circunda. Há, nesse momento, uma formulação de um eu coletivo singular, ao qual se aplica a afirmação, corriqueira, de que "tudo neste mundo é revolução", que caracteriza também o reconhecimento de uma nova afirmação de consciência que decorre na ação do homem no tempo, um novo espaço de experiência se relaciona com um novo horizonte de expectativa. O progresso buscado continuamente pela ação da aceleração se faz sentir também no meio literário e, nesse sentido, o indivíduo e a sociedade estão em contínua revolução.

Dumas e Garibaldi fazem parte disso e, portanto, não podem ser excluídos dessa revolução. Há uma contínua ebulição entre os "eus" de si mesmo e os "eus" do mundo a sua 
volta. Sendo assim, não encontramos, na obra Mémoires de Garibaldi, apenas um "eu", e sim uma multiplicidade transferida aos nossos olhos por uma multiplicidade de linguagens. $O$ autor-criador estaria divido entre vários que se estabelecem, antes, pela pena de Garibaldi e, depois, pela de Dumas.

Artigo recebido em 05 jun. 2017. Aprovado para publicação em 24 ago. 2017.

\section{Referências}

D'ALMÈRAS, Henri. Alexandre Dumas et les Trois Mousquetaires. Paris: Societé Français d'éditions littéraires et techniques, 1929.

BAKHTIN, Mikhail. O autor e a personagem na atividade estética. In: . Estética da Criação Verbal. São Paulo: Editora WMF Martins Fontes, 2011, pag. 03-192.

. O discurso no romance. In: . Questões de Literatura e de Estética: a teoria do Romance. São Paulo: Editora HUCITEC, 1988, pag. 71-210.

BARTHES, Roland. A morte do autor. In: . O Rumor da Língua. São Paulo: Editora WMF Martins Fontes, 2012, p.57-64. Da obra ao texto. In: . O Rumor da Língua. São Paulo: Editora WMF Martins Fontes, 2012, p.65-75.

BÉNICHOU, Paul. La révolucion romantique. In: . Le Sacre de L'Écrivain:1750-1830. Paris: Gallimard,2013, p.275-352.

CAVALHEIROS, Juciane S. A concepção de autor em Bakhtin, Barthes e Foucault. Londrina: Signum Estud. Ling., n.11/2, 2008, p.67-81.

CHARTIER, Roger. O que é um autor? Revisão de uma genealogia. São Carlos: EdUFSCar, 2012. DOSSE, François. O Desafio Biográfico: escrever uma vida. São Paulo: Editora da Universidade de São Paulo, 2009.

DUMAS, Alexandre. Mémoires de Garibaldi. Paris: Michel Lévy frères,1860. Vol.IIII. . Le Mois (1848-1850). Montréal: Éditions Le Joyeux Roger,2016. . Les Garibaldiens: Révolution de Sicile et de Naples. Paris: Michel Lévy 
frères,1868.

. Montevideo ou une Nouvelle Troie. Montréal: Éditions Le Joyeux Roger, 2013. . O Conde de Monte Cristo. Rio de Janeiro: Zahar,2012.

FOUCAULT, Michel. O que é um autor?. In: MOTTA, Manoel Barros (Org.). Estética: Literatura e Pintura, Música e Cinema. Rio de Janeiro: Forense Universitária, 2006, p.264-298.

GAY, Peter. O coração desvelado. São Paulo: Companhia das Letras, 1999.

GARIBALDI, Giuseppe. Memorie Autobiografiche. Firenze: G. Barbera, 1888.

LYON-CAEN, Judith. Vérité romanesque et réalité sociale. In: . La Lecture et la Vie: les usages du roman au temps de Balzac. 2006.

MENDES, Maria L. D..No limiar da História Memória: Um estudo de Mês Mémoires, de Alexandre Dumas. São Paulo: USP. p.1-321,2007.

A voz do escritor romântico: as Mémoires de Alexandre Dumas. In: Revista Travessia: Educação, Cultura, Linguagem e Arte. Florianopolis: Unioeste. ed. 03, 2008.

MIRECOURT, Eugène. Fabrique de Romans: Maison Alexandre Dumas et Compagnie. Paris: Chez tous les Marchands de Nouveautés, 1845.

MAOUROIS, André. Os três Dumas. São Paulo: Difusão europeia do livro, 1959.

MORAND, Altéve. Eugène de Mirecourt et les contemporaines: etude et réfutation. Paris: Ch.Nolet, 1855.

NETO, Joachin A.. A noção de autor em Barthes, Foucault e Agamben. In: Floema. Itapetinga: UESB. Ano VIII, n. 10, 2014, p. 153-164. 